\title{
Interactive comment on "Model simulation of ammonium and nitrate aerosols distribution in the Euro-Mediterranean region and their radiative and climatic effects over 1979-2016" by Thomas Drugé et al.
}

\section{Anonymous Referee \#2}

Received and published: 22 January 2019

The authors present work on the implementation and the evaluation of a simplified ammonium and nitrate module in the TACTIC aerosol scheme, to be utilized in the ALADIN regional climate model and to assess the direct radiative effect and climatic impact of the ammonium and nitrate aerosols over the Euro-Mediterranean region. In general, the work presented covers a scientifically sound topic, is well written, structured and the results included are original and discussed. Please find below several comments that can be taken into account before the manuscript is accepted for publication.

1) I cannot find any explanation on the statistical figures used for the model validation 
against the different observational sources included in the study. Further discussion should be elaborated on the validation methodology.

2) The limited number of bins can hamper the interpretation of results. Especially for dust, the coarsest bin ranges from 2.5 to 20 micrometers. Because of the domain of study, including several important sources of dust emissions, a large fraction of particles are excluded from the analysis. Further discussion should be devoted to the selection of the bins and why a range like that has been selected.

3) Page 9, Line 25 "These 25 stations do not have continuous data over the period 1994-2014 and we selected those with a minimum of 5 years of data, which may be non-continuous but a minimum of 5 observations is necessary for every month.". I think that 5 observations is not representative of a monthly average. How is the comparison with model results done? Do you estimate a monthly average from those 5 observations? Or do you extract model data for those 5 time steps and then compare with observations?

4) Are the evaluation results different for MODIS and AERONET at AERONET sites? Or, better side, is there any significant difference when evaluating the model against satellite and AERONET in those locations where you have AERONET observations?

5) Can you do some partitioning between ammonia and nitrate? Can you somehow estimate which is the individual contribution of each component to the direct radiative forcing?

Last, it would help readability if equations are numbered within the manuscript.

Interactive comment on Atmos. Chem. Phys. Discuss., https://doi.org/10.5194/acp-2018-1101, 2018. 